\title{
EFFECT OF OKY-1581, A THROMBOXANE SYNTHETASE INHIBITOR, ON CORONARY THROMBOSIS IN THE CONSCIOUS DOG
}

\author{
MICHAEL J. SHEA, FDWARD M. DRISCOLL, JOSEPH L. ROMSON, BERTRAM PITT and BENEDICT R. LUCCHESI * \\ Departments of Pharmacology and Internal Medicine (Cardiology), The Unitersity of Michigan Medical School. Ann Arbor, Michigan \\ 48109, U.S.A
}

Received 7 February 1984, revised MS received 5 June 1984. accepted 17 July 1984

M.J. SHEA, E.M. DRISCOLL. J.L. ROMSON, B. PITT and B.R. LUCCHESI, Effect of OKY-1581, a thromboxane synthetase inhibitor, on coronary thrombosis on the conscious dog, European J. Pharmacol. 105 (1984) 285-291.

OKY-1581, a new thromboxane synthetase inhibitor, was studied in a conscious canine model of coronary thrombosis. After thoracotomy with placement of a left circumflex coronary artery flow probe and implantation of an electrode into the circumflex artery, animals were assigned randomly to the following groups: $0.9 \% \mathrm{NaCl}$ vehicle control or OKY $15811 \mathrm{mg} / \mathrm{kg}$ every $4 \mathrm{~h}$ intravenously for $24 \mathrm{~h}$. During the drug treatment period, a $50 \mu \mathrm{A}$ anodal current was passed through the circumflex electrode. and venous blood was obtained for platelet aggregation studies. As compared to control animals, the OKY-1581 treated animals developed a greater mean coronary flow at the end of the treatment period, smaller thrombi by wet weight, smaller infarcts, and fewer ventricular arrhythmias. Ex vivo platelet aggregation studies revealed significant inhibition of aggregation to standard aggregating agents for the drug treated group only. OKY-1581 is an effective antitbrombotic agent which maintains coronary flow after a thrombogenic stimulus, presumably via blockade of the synthesis of thromboxane by blond platelets.

Coronary artery thrombosis Thromboxane synthetase inhibitor Platelet aggregation Antithrombotic agent

\section{Introduction}

Recent antithrombotic strategies have emphasized inhibition of selected platelet functions including aggregation, adhesion and production of vasoactive metabolites of the arachidonic acid pathway, e.g. thromboxane $\mathrm{A}_{2}$ (Moncada and Vane, 1979; Packham and Mustard, 1980). An appealing approach is thromboxane synthetase inhibition with a resultant decrease in thromboxane generation by blood platelets and circulating leukocytes, thereby leaving the endothelial prostacyclin production presumably intact. Indeed, in-

\footnotetext{
* To whom all correspondence should be addressed: Department of Pharmacology, M6322 Medical Science Building I, University of Michigan Medical School, Ann Arbor, Michigan 48109 , U.S.A.
}

hibition of thromboxane production may result in the utilization of platelet cyclic endoperoxides by the vascular endothelium with an increase in prostacyclin production (Marcus et al., 1980).

Several drugs have been reported as inhibitors of thromboxane synthetase, principally imidazole and its derivatives (Moncada et al., 1977; Tai and Yuan, 1978). One of the imidazoles, dazoxiben, has been studied extensively in the laboratory and in man and has shown promise in conditions ranging from angina pectoris to endotoxemia (Anonymous, 1983). Preliminary studies with OKY-1581 (sodium (E)-3-[4-(3-pyridylmethyl) phenyl]-2-methylacrylate) and its hydrochloride salt, OKY-1555, have indicated that they are potent and selective inhibitors of thromboxane synthetase in experimental systems involving $\mathrm{PGH}_{2}$ and incubated rabbit platelets (Feuerstein and Ramwell, 1981) and lipopolysaccharide stimulated rat macrophages (Miyamoto et al., 1980). 
Using a canine model of coronary artery thrombosis recently developed in our laboratory (Romson et al. 1980). we hypothesized that the antiplatelet effect of OKY-1581 might limit coronary thrombosis thereby lessening the subsequent adverse events of myocardial infarction and arrhythmia generation.

\section{Materials and methods}

\subsection{Surgical procedure}

Male mongrel dogs, $15-20 \mathrm{~kg}$, were anesthetized with intravenous sodium pentobarbital $(30 \mathrm{mg} / \mathrm{kg}$ ) and artificially ventilated. A lead II electrocardiogram (ECG) was monitored throughout surgery. Using aseptic technique. cannulae were placed in the left common carotid artery and jugular vein and exteriorized through the nape of the neck. After a left thoracotomy, the heart was suspended in a pericardial cradle and the proximal left circumflex coronary artery ( $\mathrm{LCX}$ ) was isolated from the surrounding tissues. A 28 gauge Teflon-coated silver wire with $5 \mathrm{~mm}$ of the tip of a 25 gauge hypodermic needle secured on the wire's leading end was inserted into the LCX and affixed to the heart with two superficial 3-0 silk epicardial sutures. A pre-calibrated electromagnetic flow probe (Carolina Instrument Co.) was placed on the LCX 2-3 $\mathrm{mm}$ proximal to the silver wire insertion and affixed to the epicardial surface of the heart with 2-0 silk suture. The zero flow baseline was established by transient total occlusion of the LCX followed by release. Coronary blood flow was measured with a square-wave electromagnetic flow meter (Carolina Medical Electronics, Inc.). The pericardium and chest were closed in layers. Grass disc electrodes were tunneled subcutaneously near the right foreleg and left hindleg and exteriorized along with the intracoronary wire and flow probe through the thoracotomy incision. The dogs were given a single intramuscular injection of ampicillin $(3 \mathrm{mg} / \mathrm{kg})$. Cannulae were flushed with $0.9 \% \mathrm{NaCl}$ and a dilute porcine heparin solution (50 units in $0.3 \mathrm{ml}$ ) (Sigma) was placed in the cannulae to maintain patency.

\subsection{Electrical stimulation of the circumflex artery and drug treatment}

Twenty-four $h$ after the completion of surgery. the animal's heart rate, blood pressure. electrocardiogram. and coronary blood flow were monitored. Animals were studied further only if: (1) they were free of electrocardiographic evidence of myocardial injury and/or necrosis. (2) they had no evidence of significant arrhythmias (fewer than 5 premature ventricular complexes per $\min$ ), (3) they had a normal phasic pattern of coronary blood flow. The animals were returned to their respective kennels and the study protocol was initiated on the second postoperative day if the above stated criteria were satisfied.

The experimental protocol, briefly outlined, was as follows. Day 1: surgery: day 2: recovery; day 3 : venous blood for platelet aggregation, treatment with drug or vehicle control every $4 \mathrm{~h}$ for $24 \mathrm{~h}$. electrical stimulation of the LCX for $24 \mathrm{~h}$ with concomitant ECG monitoring, venous blood for platelet aggregation after the second dose of drug (during electrical stimulation of the LCX); day 4 : venous blood for platelet aggregation; sacrifice.

Animals were given $0.9 \% \mathrm{NaCl}$ or $\mathrm{OKY}-1581$ according to a random numbers table. OKY-1581, $1 \mathrm{mg} / \mathrm{kg}$. (Ono Pharmaceutical Co.. Osaka. Japan) was administered to the animals every $4 \mathrm{~h}$ intravenously for the next $24 \mathrm{~h}$.

After the initial dose of drug or $0.9 \% \mathrm{NaCl}$. anodal current from a $9 \mathrm{~V}$ battery was delivered to the intimal surface of the LCX via the Tefloncoated wire. The current output of $50 \mu \mathrm{A}$ was adjusted through a $250000 \Omega$ potentiometer placed in series. The ECG electrode leads were connected to a telemetry transmitter. The potentiometer with the battery supply and FCG transmitter were kept in a nylon jacket which allowed the dog unrestricted movement.

Electrocardiographic data were received via telemetry and in turn were recorded on a tape recorder programmed to record $28 \mathrm{~s}$ of tracing every $15 \mathrm{~min}$. The lape was played back later through a Grass model 7 oscillographic recorder for analysis of arrhythmias.

The $50 \mu \mathrm{A}$ current to the LCX was continued for $24 \mathrm{~h}$ (while drug dosing was continuing). 
Venous blood for platelet studies was obtained after the second drug administration interval during the period of electrical stimulation and again at the end of the electrical stimulation at $24 \mathrm{~h}$. The animals were monitored for $30 \mathrm{~min}$ for heart rate, blood pressure, electrocardiogram and coronary' blood flow by direct recording on a Grass model 7 oscillographic recorder. The animals then were anesthetized with $30 \mathrm{mg} / \mathrm{kg}$ of sodium pentobarbital and the heart was exposed as described above. Ventricular fibrillation was induced by a DC current and the heart was removed. The LCX in the area of the wire insertion was dissected free and the artery was opened lengthwise. The wet thrombus was removed intact from the intima and weighed. The heart then was "breadloafed" from apex to base into $7 \mathrm{~mm}$ thick transverse slices and incubated in 2,3,5-triphenyltetrazolium chloride (TTC) (Sigma) for $30 \mathrm{~min}$ at $37^{\circ} \mathrm{C}$. TTC stains normal tissues brick red due to the formazan dye resulting from the reduction of TTC by the dehydrogenases of viable myocardium. The irreversibly injured areas do not react with TTC and appear as pale gray regions which are distinguished easily for purposes of quantification. Both the nonstained and stained areas were removed and weighed to permit calculation of infarct mass which is expressed as a percent of the total left ventricle by weight.

Sham operated controls with placement of the wire electrode and additional instrumentation were not used for this study. Previous work (Romson et al., 1980, and unpublished observations) suggests that sham operated animals do not spontaneously develop occlusive thrombi, myocardial infarction or arrhythmias as a result of the instrumentation.

\subsection{Platelet aggregation studies}

Platelet aggregation studies were performed using previously described spectrophotometric methods (Romson et al., 1980) utilizing a Bio/Data platelet aggregometer. Platelet rich plasma was prepared by collecting foreleg venous blood in 1.0 $\mathrm{ml}$ of $3.8 \%$ sodium citrate to a total volume of 10 $\mathrm{ml}$. This was centrifuged at $310 \times \mathrm{g}$ for $3 \mathrm{~min}$ to obtain the platelet rich plasma fraction and then at $2200 \times g$ for $10 \mathrm{~min}$ to obtain the platelet poor fraction. Platelet rich plasma was diluted with platelet poor plasma to a platelet count of $200000 / \mathrm{mm}^{3}$ before use in the aggregation assays. All platelet samples were assayed within $2 \mathrm{~h}$ of the time of blood collection. Aggregation was initiated under 3 different conditions using a $50 \mu 1$ aliquot of aggregating agent added to $450 \mu 1$ of diluted platelet rich plasma. Aggregating stimuli included: collagen (1:80 dilution of Ethicon Collagen Dispersion - TD150); $5.0 \mu \mathrm{g}$ ADP (Sigma); and arachidonic acid (Sigma) $0.65 \mathrm{mM}$ with an additional $10 \mu \mathrm{l}$ of L-epinephrine (Sigma), $0.55 \mu \mathrm{M}$ in saline at $\mathrm{pH} 3$.

Thromboxane measurements were not made in this study.

\subsection{Statistical methods}

All data are expressed as the mean \pm standard error of the mean. The Student's t-test for unpaired observations was used to evaluate the statistical significance of the hemodynamic and infarct data (Remington and Schork, 1970). The MannWhitney test was used to evaluate the statistical significance of the arrhythmia and platelet aggregation data (Conover, 1980). A P value of $<0.05$. treated vs. control, was considered to be statistically significant.

\section{Results}

OKY-1581 had no significant effect on heart rate. blood pressure, the electrocardiogram, or coronary blood flow when administered acutely. At the end of the $24 \mathrm{~h}$ period of drug administration and electrical stimulation, the mean arterial blood pressures for both drug and control groups had decreased. Before OKY-1581 administration the mean arterial pressure was $111 \pm 6 \mathrm{mmHg}$, whereas at the end of the experiment blood pressure was $93 \pm 10 \mathrm{mmHg}$. Observations were complete for only five of the seven animals studied. For the control group the baseline blood pressure was $109 \pm 5 \mathrm{mmHg}$, whereas at the completion of the study the blood pressure was $104 \pm 3 \mathrm{mmHg}$ $(\mathrm{n}=11)$

There was no difference in the baseline mean 
coronary blood flows for the $0.9 \% \mathrm{NaCl}$ treated or drug treated animals: $20.4 \pm 1.3 \mathrm{ml} / \mathrm{min}$ vs. 22.1 $\pm 1.1 \mathrm{ml} / \mathrm{min}$, respectively. At the end of the experimental period, mean coronary flow was significantly greater in the OKY -1581 treated group than the control group: $11.1 \pm 4 \mathrm{ml} / \mathrm{min}$ vs. $2 \pm 1.6$ $\mathrm{ml} / \mathrm{min}$, respectively ( $\mathrm{P}<0.05$, treated vs. control). In the control group nine of eleven animals had an absence of LCX coronary blood flow at the end of the study period. Of the remaining two animals. one had a modest reduction in LCX coronary flow ( 24 to $18 \mathrm{ml} / \mathrm{min}$ ), whereas the other had a marked reduction $(26$ to $4 \mathrm{ml} / \mathrm{min})$. In the drug treated group, LCX coronary flow was absent in three of seven animals at the end of the experimental period, whereas the remaining four animals had essentially no change in coronary flow from the beginning to the end of the experimental period (22 vs. $19.5 \mathrm{ml} / \mathrm{min}$ ).

The size of the thrombi in the drug treated group was one-fourth of that in the $0.9 \% \mathrm{NaCl}$ vehicle control group (table 1). There was no apparent relationship between thrombus size and the coronary blood flow: comparatively small thrombi were occasionally noted to be associated with an absence of coronary blood flow, however, large thrombi were always occlusive.

Left ventricular infarction was considerably smaller in the drug treated group as compared to the control group (table 1). This observation also applied when infarct mass was expressed as a percentage of the left ventricle to correct for differences in heart weights. Drug treated animals with nonocclusive thrombi and maintenance of coronary flow had the smallest infarctions. For the

\section{TABLE 1}

Effect of OKY-1581 on thrombus size and myocardial infarction after electrical injury of the circumflex artery

\begin{tabular}{lcc}
\hline & $\begin{array}{c}\text { Control } \\
(\mathrm{n}=11)\end{array}$ & \multicolumn{1}{c}{$\begin{array}{l}\text { OKY-1581 } \\
(\mathrm{n}=7)\end{array}$} \\
\hline Thrombus wet weight (mg) & $21.8 \pm 3.7^{\mathrm{a}}$ & $5.0 \pm 1.5^{\mathrm{b}}$ \\
Left ventricular infarction $(\mathrm{g})$ & $15.2 \pm 1.3$ & $4.7 \pm 2.1^{\mathrm{h}}$ \\
Left ventricle $(\mathrm{g})$ & $74.8 \pm 5.2$ & $75.1 \pm 3.1^{\circ}$ \\
Infarct/left ventricle ( $(6)$ & $20.3 \pm 2.2$ & $6.3 \pm 2.9^{\mathrm{b}}$ \\
Total heart $(\mathrm{g})$ & $110.1 \pm 7.4$ & $114.1 \pm 7$
\end{tabular}

Mean \pm S.E.M. ${ }^{\mathrm{b}} \mathrm{P}<0.05$. treated vs. control.

\section{TABLE: 2}

Frequency of ventricular arrhythmias during the $24 \mathrm{~h}$ of electrical stimulation of the circumflex artery

\begin{tabular}{|c|c|c|}
\hline & \multicolumn{2}{|c|}{ PVC $/ \mathrm{HIR}(T)^{a}$} \\
\hline & $\begin{array}{l}\text { Control } \\
(n-11)\end{array}$ & $\begin{array}{l}O K Y-1581 \\
(n=7)\end{array}$ \\
\hline $0-6 \mathrm{~h}$ & $4.6 \pm 2.8^{h}$ & $1.7 \pm 1.7$ \\
\hline $7-12 \mathrm{~h}$ & $29.3 \pm 9.6$ & $11.4+7.7$ \\
\hline $13-18 \mathrm{~h}$ & $78.8 \pm 10.8^{\circ}$ & $23.1 \pm 15.5^{d}$ \\
\hline $19-24 \mathrm{~h}$ & $98.1+1.4^{\circ}$ & $27.3 \pm 17.6^{d}$ \\
\hline
\end{tabular}

"Premature ventricular contractions expressed as a percentage of the heart rate. ${ }^{n}$ Mean + S.F.M. ${ }^{\prime} n=10{ }^{d} p<0.05$ treated vs. control.

other drug and contrtol animals, there was no direct relationship between thrombus size and infarct size.

Drug treated animals had fewer ventricular arrhythmias over the last $12 \mathrm{~h}$ of the study period than the control groups (table 2). This difference may, in part. be related to the time course of thrombus formation. In this experimental model. coronary thrombosis most frequently occurs during the 4 th to 11 th $\mathrm{h}$ of electrical stimulation (unpublished observations) with the subsequent progressive development of electrocardiographic changes and disturbances in cardiac rhythm. Major differences in the control and treated groups might not be expected until the last $12 \mathrm{~h}$ of study.

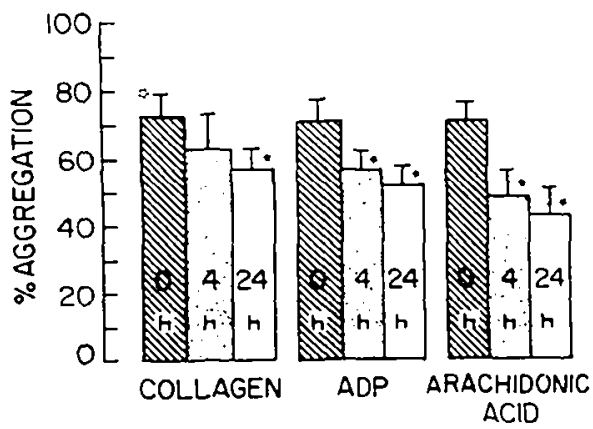

Fig. 1. Each bar represents the mean \pm S.E.M. $(n=6)$ from an aggregating condition at one of three time points: $0 \mathrm{~h}$, the pre-drug baseline: $4 \mathrm{~h}$. after the second dose of drug: and $24 \mathrm{~h}$. after $24 \mathrm{~h}$ drug administration with concurrent electrical stimulation of the left circumflex coronary artery. OKY-1581 was administered every $4 \mathrm{~h}$ as a $1 \mathrm{mg} / \mathrm{kg}$ i.v. injection. $\dot{x} \pm$ S.F.M. $* \mathrm{P}<0.05$ for 24 or 4 vs. $0 \mathrm{~h}$. 


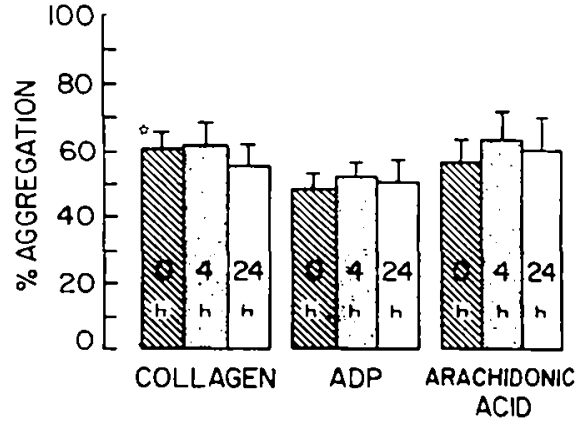

Fig. 2. Each bar represents the mean \pm S.E.M. $(n=7)$ for an aggregating condition at one of three time points: $0 \mathrm{~h}$, the pre-saline control $(0.9 \% \mathrm{NaCl})$ baseline; $4 \mathrm{~h}$, after the second dose of saline control $(0.8 \% \mathrm{NaCl})$ and $24 \mathrm{~h}$. after $24 \mathrm{~h}$ of saline control $(0.9 \% \mathrm{NaCl})$ administration with concurrent electrical stimulation of the left circumflex coronary artery. $s \bar{x} \pm$ S.E.M.

One animal in the control group died suddenly in the 11 th $\mathrm{h}$ of electrical stimulation with ventricular fibrillation as the terminal arrhythmia. In the drug treated group, five of seven animals were arrhythmia-free including three animals with small areas of irreversibly injured myocardium as determined by histochemical staining with triphenyltetrazolium. In the control animals, the ventricular arrhythmias typically were extended runs of ventricular tachycardia, occasionally multiform. In the drug treated group, the arrhythmias were qualitatively similar.

OKY-1581 inhibited platelet aggregation in response to standard aggregation conditions (fig. 1). In comparing the $4 \mathrm{~h}$ and $24 \mathrm{~h}$ aggregations to the pre-drug baseline $(0 \mathrm{~h})$, significant inhibition of aggregation was evident at each point for ADP and arachidonic acid. For the collagen aggregatory condition. a significant difference was evident only at $24 \mathrm{~h}$.

For the control animal, no significant differences were observed for any of the time points for any of the aggregating conditions as compared to the baseline states (fig. 2).

\section{Discussion}

OKY-1581, a thromboxane synthetase inhibitor, has no direct vascular effects as suggested by its lack of acute hemodynamic effects during intravenous administration. Our experimental design did not provide for an assessment of the chronic hemodynamic effects of thromboxane synthetase inhibition since the studies were terminated at $24 \mathrm{~h}$ after the initiation of drug therapy. Preliminary studies with dazoxiben have not revealed any clinically relevant changes in heart rate or blood pressure during subacute administration in humans (Tyler et al., 1981).

OKY-1581 treated animals maintained coronary flow at the end of the experimental period in contrast to control animals. While a direct relationship of the size of the thrombus to the degree of coronary flow was not evident, large thrombi were usually occlusive.

We assume the reduction in coronary flow in this model to represent transient total occlusion of the circumflex artery due to intraluminal thrombi which embolize spontaneously (Folts et al., 1982). At some point, total occlusion may occur when a "critical closing pressure" is reached due to thrombus causing a stenosis greater than $90 \%$ of the circumflex diameter with or without supervening coronary vasomotor activity (Elzinga and Skinner, 1975; Burton, 1965; Uchida et al., 1975; Santamore et al., 1980). A recent study by Sellers and $\mathrm{Ku}$ (1982) has demonstrated the ability of thrombin to promote coronary artery vasoconstriction only after endothelial damage had been produced. A similar mechanism might be operative in the present study. Thus, the induction of endothelial injury by an electrical current and the subsequent development of platelet adhesion and thrombosis would bring about formation of thrombin which could then cause coronary artery vasospasm which would convert a partially obstructing platelet thrombus to a totally occlusive thrombus. This could account for our finding of a markedly decreased coronary artery flow despite the presence of a relatively small thrombus. Our model does not differentiate whether the primary effect of OKY-1581 is due to antithrombotic or antispasmodic properties. However, the ability of nitroglycerin injection to restore the coronary flow pattern during the phasic oscillations in coronary flow would suggest that aggregation of platelets at the site of injury can lead to coronary artery 
vasomotion (Sellers and $\mathrm{Ku}, 1982$; Romson and Lucchesi, 1980). Maintenance of coronary flow was most important in limitation of infact size as animals with small nonocclusive thrombi had the smallest infarctions. Additional beneficial effects of OKY-1581 on ischemic myocardium cannot be excluded, especially in view of recent work suggesting that OKY-1581, as well as dazoxiben, limits the extension of ischemic damage caused by coronary artery ligation in cats (Burke et al.. 1983a.b).

The decrease in ventricular arrhythmias in drug treated animals with no evidence of infarction and maintenance of coronary flow was not a surprising result. However. even those drug-treated animals with infarction had fewer ventricular arrhythmias over the last $12 \mathrm{~h}$ of electrical stimulation of the LCX as compared to control animals. The beneficial effect of OKY -1581 here is unclear. Coker and co-workers have described thromboxane release from ischemic canine myocardium associated with ventricular arrhythmias (Coker et al., 1981). Fxtending their studies they found that dazoxiben seemed to prevent ventricular fibrillation following reperfusion after a 40 min coronary artery ligation in greyhounds (Coker and Parratt, 1983). The role of thromboxane and thromboxane synthetase inhibitors in ischemic arrhythmias will need further investigation.

In animals which were treated with OKY -1581 there was inhibition of platelet aggregation in response to collagen. ADP and arachidonic acid. Inhibition was evident at $4 \mathrm{~h}$ for ADP and arachidonic acid and for all three aggregating agents by the end of the experimental period. The platelet aggregation responses to these different aggregating agents are compatible with the inhibition of platelet thromboxane synthetase by OKY 1581. The moderate inhibition of platelet aggregation by a selective thromboxane synthetase inhibitor such as OKY-1581 is most likely due to the build-up of proaggregatory cyclic endoperoxides, the lack of complete thromboxane $A_{2}$ inhibition, or the inability of OKY-1581 to limit the proaggregatory stimulus from other platelet products. e.g. serotonin. It is likely that the effect of OKY1581 in limiting thrombus size is related to its inhibition of platelet aggregation in view of the fact that control animals had no significant change in aggregation patterns during the experimental period.

\section{Acknowledgements}

This study was supported by a grant from the NHLBI-HL. 27817-01. Dr. Michael Shea was a Postdoctoral Fellow of the Michigan Heart Association. Dr. Joseph Romson was supported by a Predoctoral Fellowship from the Pharmaceutical Manufacturers Association Foundation. We acknowledge the excellent secretarial assistance of Dixic Thomas.

\section{References}

Anonymous, 1983, Dazoxiben. Lancet 1. 627.

Burke. S.F... D.J. Lefer and A.M. Lefer, 1983a, Cardioprotective actions of a selective thromboxane synthetase inhibitor in acute myocardial ischemia. Arch. Int. Pharmacodyn. 26.5 76.

Burke, S.E.. A.M. L.efer, G.M. Smith and J.B. Smith. 1983h. Prevention of extension of ischemic damage following acute myocardial ischemia by dazoxiben. a new thromboxane synthetase inhibitor, Br. J. Clin. Pharmacol. 15. 975.

Burton. A.C., 1965, Physiology and Biophysics of the (irculation (Yearbook Publishers, Chicago) p. 89

Coker. S.J. and J.R. Parratt, 1983. Effects of dazoxiben on arrhythmias and ventricular fibrillation induced by coronary artery occlusion and reperfusion in anesthetized greyhounds. Br. J. Clin. Pharmacol. 15. 875

Coker, S.J., J.R. Paratt. I.M. I.edingham and I.J. Zeitlin. 1981. Thromboxane and prostacyclin release from ischemic myocardium in relation to arrhythmias. Nature 291, 323.

Conover, W.J.. 1980. Practical Nonparametric Statistics (John Wiley and Sons. Inc.. New York) p. 215.

Elzinga, W.E. and D.B. Skinner, 1975, Hemodynamic char acteristics of critical stenosis in canine coronary arteries, $\mathrm{J}$. Thorac. Cardiovasc. Surg. 69, 217

Feuerstein. N. and P.W. Ramwell, 1981. OKY-1581, a potential selective thromboxane synthetase inhibitor. Furopean $J$ Pharmacol. 69. 533.

Folts. J.D., K. Gallagher and (;. Rowe, 1982, Bloond flose reductions in stenosed canine coronary arteries: vasospasm or platelet aggregation?, Circulation 65, 248 .

Marcus, A.J., B.B. Weksler, F.A. Jaffe and M.J. Broekman, 1980. Synthesis of prostacyclin from platelet-derived endoperoxide by cultured human epithelial cells, J. Clin. Invest 66. 979.

Miyamoto. T.. K. Taniguchi. T. Tanouchi and F. Hirata. 1980, Selective inhibitor of thromboxane synthetase: pyridine and its derivatives, Adv. Prost. Thrombox. Res. 6, 443

Moncada. S., S. Bunting, K. Mullane. P. Thorogood, J.R. Vane, A. Rav. and P. Needleman, 1977. Imidazole: a selective 
inhibitor of thromboxane synthetase. Prostaglandins 13. 611.

Moncada, S. and J.R. Vane, 1979, Arachidonic acid metabolites and the interactions between platelets and blood vessel walls, N. Engl. J. Med. 300. 1142.

Packman, M.A. and J.F. Mustard, 1980. Pharmacology of platelet-affecting drugs. Circulation 62 (Suppl. V). 26.

Remington, R.D. and M.A. Schork, 1970. Statistics with Applications to the Biological and Health Sciences (Prentice-Hall. New Jersey) p. 148.

Rumson, J.L.. D.W. Haack and B.R. Lucchesi, 1980. Electrical induction of coronary artery thrombosis in the ambulatory canine: a model for in vivo evaluation of antithrombotic agents. Thromb. Res. 17,841.

Romson. J.L. and B.R. Lucchesi, 1980. Experimental myocardial ischemia provoked by platelet aggregation and coronary artery spasm. Unstable Angina Pectoris (Thieme-Stratton, Inc.. New York) p. 13.
Santamore, W.P., P. Walinsky, A.A. Bove, R.H. Cox, R.A. Carey and J.F. Spann, 1980, The effects of vasoconstriction on experimental coronary artery stenosis. Am. Heart J. 100. 852.

Scllers, B.M. and D.D. Ku, 1982, Effects of temporary myocardial ischemia on coronary vascular contractile responses in dogs, Fed. Proc. 41. 1766.

Tai, H.H. and B. Yuan. 1978. On the inhibitory potency of imidazole and its derivatives on thromboxane synthetase. Biochem. Biophys. Res. Commun. 80. 236.

Tyler, H.M. C.A. Saxton and M.J. Parry. 1981. Administration to man of UK-37.248-0.1, a selective inhibitor of thromboxane synthetase, Lancet 1, 629 .

Lichida, Y.. N. Yoshimoto, S. Murao, 1975. Cyclic fluctuations in coronary blood pressure and flow induced by coronary artery constriction. Jap. Heart J. 16, 454. 